NASA Technical Memorandum 107491

AIAA-97-2837

\title{
Imaging Fluorescent Combustion Species in Gas Turbine Flame Tubes: On Complexities in Real Systems
}

Y.R. Hicks

Lewis Research Center

Cleveland, Ohio

R.J. Locke

NYMA, Inc.

Brook Park, Ohio

R.C. Anderson and M. Zaller

Lewis Research Center

Cleveland, Ohio

H.J. Schock

Michigan State University

East Lansing, Michigan

Prepared for the

33rd Joint Propulsion Conference

cosponsored by AIAA, ASME, SAE, and ASEE

Seattle, Washington, July 6-9, 1997

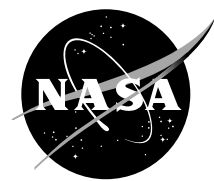

National Aeronautics and

Space Administration 
Trade names or manufacturers' names are used in this report for identification only. This usage does not constitute an official endorsement, either expressed or implied, by the National Aeronautics and Space Administration. 


\title{
IMAGING FLUORESCENT COMBUSTION SPECIES IN GAS TURBINE FLAME TUBES: ON COMPLEXITIES IN REAL SYSTEMS
}

\author{
Y.R. Hicks, R.C. Anderson and M. Zaller \\ National Aeronautics and Space Administration \\ Lewis Research Center \\ Cleveland, Ohio 44135 \\ R.J. Locke \\ NYMA, Inc. \\ Brook Park, Ohio 44142 \\ H.J. Schock \\ Professor, Department of Mechanical Engineering \\ Michigan State University \\ East Lansing, Michigan
}

\begin{abstract}
Planar laser-induced fluorescence (PLIF) is used to visualize the flame structure via $\mathrm{OH}, \mathrm{NO}$, and fuel imaging in kerosine-burning gas turbine combustor flame tubes. When compared to simple gaseous hydrocarbon flames and hydrogen flames, flame tube testing complexities include spectral interferences from large fuel fragments, unknown turbulence interactions, high pressure operation, and the concomitant need for windows and remote operation. Complications of these and other factors as they apply to image analysis are considered. Because both $\mathrm{OH}$ and gas turbine engine fuels (commercial and military) can be excited and detected using $\mathrm{OH}$ transition lines, a narrowband and a broadband detection scheme are compared and the benefits and draw-backs of each method are examined.
\end{abstract}

\section{Introduction}

$\mathrm{OH}$ planar laser-induced fluorescence (PLIF) is commonly used to image and characterize combustion processes. Generally, it is a relatively simple technique to implement. Additionally, a large spectroscopic database exists for $\mathrm{OH}$; there is good separation between its rovibronic lines and little spectral interference has been encountered for most of the combustion environments in which OH PLIF has been applied. OH is also a major combustion intermediate that marks the flame zone and its concentration can be used to derive temperature. OH PLIF

Copyright (C) 1997 by the American Institute of Aeronautics and Astronautics, Inc. No copyright is asserted in the United States under Title 17, U.S. Code. The U.S. Government has a royalty-free license to exercise all rights under the copyright claimed herein for Governmental Purposes. All other rights are reserved by the copyright owner. has been shown to be a very effective two-dimensional visualization tool for examining flow uniformity and mixing.

Most of the previous $\mathrm{OH}$ fluorescence efforts were performed in low-pressure and atmospheric-pressure combustion systems such as small flat flame and Bunsen burners. In these cases, the typical fuel was hydrogen or methane. More recent efforts used ethane and ethylene as fuels. These low pressure burners typically have the advantage of using large windows (or no windows at all); and in many cases, researchers have direct access to the facility during tests. Flames burning above atmospheric pressure tend to have more limited optical access due to the need for a structurally sound containment vessel (or pipe) and required windows. However, it is in the high pressure environment ( $\geq 6 \mathrm{~atm})$ that most ground and air-based propulsion systems operate. To date, little research has been done at these pressure levels using laserinduced fluorescence methods.

Real air-based propulsion systems generally use liquid fuel where spray flames impose the complexity of a potentially multiphase system. Overlying spectral interferences with the desired fluorescence signal can arise from elastically scattered light from the liquid fuel, and from blackbody radiation if the flame is luminous. Heptane-air spray flames have been studied at atmospheric pressure ${ }^{1}$ using PLIF of $\mathrm{OH}$ and $\mathrm{CH}$, and at pressures up to $10 \mathrm{~atm} .{ }^{2,3}$ The latter work employed PLIF of $\mathrm{OH}$, provided a theoretical examination of $\mathrm{NO}$ and $\mathrm{O}_{2}$, and found large interferences from soot precursors. 
Other studies at high pressure using small burners include the work of Battles et al., ${ }^{4}$ who developed a method for quantifying fluorescence signals in the burnt gases region of a methane-air flat flame burner for $\mathrm{OH}$, $\mathrm{NO}$, and $\mathrm{O}_{2}$ at pressures up to $10.2 \mathrm{~atm}$. DiRosa et al., ${ }^{5}$ developed spectral models for $\mathrm{NO}$ and $\mathrm{O}_{2}$ in fuel-lean methane- $\mathrm{O}_{2}$ flames from 1 to $10 \mathrm{~atm}$. Neij and Aldén ${ }^{6}$ used a two-photon PLIF technique to image water vapor in a high-pressure cell at $\sim 10 \mathrm{~atm}$.

More applied uses of PLIF include species measurements in internal combustion engines. Suntz et al used PLIF of OH to examine premixed propane-air flames in a simulation piston-cylinder engine. ${ }^{7}$ Engine speeds of $500 \mathrm{rpm}$ and pressures to $7.5 \mathrm{~atm}$ were simulated in a square cylinder, which was limited to single cycle events. Schipperijn et al also looked at a piston-cylinder (circular) burning a propane-air mixture at $300 \mathrm{rpm}$ and a 5:1 compression ratio with firing occurring every third cycle. ${ }^{8}$ Felton et al also examined a piston-cylinder engine burning a propane-air mixture. ${ }^{9}$ The engine operated at $600 \mathrm{rpm}$ and achieved pressures to $\sim 13 \mathrm{~atm}$. Andresen et al. used PLIF of NO and isooctane fuel and laser-induced predissociative fluorescence (LIPF) for imaging $\mathrm{OH}$ at pressures to $\sim 20 \mathrm{~atm} .{ }^{10}$ Other applied work includes Stepowski et al, who used PLIF of $\mathrm{OH}$ and velocity measurements with a phase Doppler instrument to investigate flame stabilization of a methanol-air spray flame from an air-blast injector. ${ }^{11}$ They used single shot analysis of lift-off location (including height and radius) to validate a spray flame model. Finally, Versluis et al examined a $100 \mathrm{~kW}$ natural gas atmospheric pressure burner using PLIF of NO and predissociated fluorescence of OH. ${ }^{12}$ The impetus for the study was a concern for emissions reduction in ground-based power plants. Their work resulted in an improved burner design that produces less NO.

The combustion environment of the present study is unique in its combination of high temperature, high pressure, multiphase combustion, large continuous flow rates, multicomponent fuel, and multiple type and quantity of fuel injection points. It is somewhat more complex than earlier work performed using a single fuel injector because the present focus lies in the primary reaction zone rather than in the burnt gases region. ${ }^{13,14}$ The efforts to characterize both the primary zone and the burnt gases zone motivate this report.

We discuss the complexities encountered during this work, which includes spectral interferences from large fuel fragments, unknown turbulence interactions, high pressure operation, and optical scattering. The effects of these complicating factors upon image analysis are also considered. Two detection schemes are compared and the benefits and drawbacks of each method are examined.

\section{Experimental Hardware}

Test Hardware

The combustion facility supplies nonvitiated air at temperatures to $866 \mathrm{~K}$ and pressures to $20 \mathrm{~atm}$ to two optically-accessible test stands. The fuel used is kerosine (Jet-A or JP-5). Figure 1 shows schematic drawings of the combustion shells for each test stand. The housings are water-cooled and the liner material is a castable ceramic. Each test stand employs the same window design. The UV grade fused silica windows measure $3.8 \mathrm{~cm}$ axially, $5.1 \mathrm{~cm}$ in the direction normal to the rig centerline, and are $1.3 \mathrm{~cm}$ thick. The inner surfaces of the windows are cooled by a thin film of $\mathrm{N}_{2}$.

One test rig, a single cup flame tube combustor, has an inlet flow path area that measures $7.6 \times 7.6 \mathrm{~cm}$. It is used to characterize fuel injector performance. The second test rig supports multiple cup (sector) tests; it is used to assess the interaction between fuel injectors. The two combustion rigs are henceforth designated "flame tube" and "sector."

In the flame tube, two fuel injectors offering different lean direct injection schemes were examined. For each case, the injector exit obscures the leading $6 \mathrm{~mm}$ of the window, leaving $3.2 \mathrm{~cm}$ available for flowfield imaging.

The sector inlet flow path area measures $21.6 \times 21.6 \mathrm{~cm}$. Within this area, three fuel injector domes are fitted. Each dome consists of an array of fuel injectors of the same type. Two types of fuel-lean burning injection systems were used. The outer domes (top and bottom) are composed of lean premixed prevaporized injectors. The center dome injectors operate as partially-premixed swirlstabilized injectors. The exit plane of the center dome is $\sim 4.6 \mathrm{~cm}$ upstream of the exit plane of the outer domes. The top dome obscures the first $8 \mathrm{~mm}$ of the windows.

\section{Optical Diagnostics Facility}

\section{Lasers}

The laser system used for acquiring the PLIF images consists of a Continuum Nd:YAG-pumped (NY-81C) dye laser (ND60), with a frequency doubler/mixer (UVX). The dye laser output was doubled to provide the desired $\mathrm{OH}(1,0)$ band excitation near $283 \mathrm{~nm}$ at $\sim 16 \mathrm{~mJ} /$ pulse for $\mathrm{OH}$ or fuel excitation, or mixed with residual IR after doubling to provide NO $\gamma(0,0)$ band excitation around $225 \mathrm{~nm}$ with $\sim 4 \mathrm{~mJ} / \mathrm{pulse}$. The Nd:YAGlaser $2 \mathrm{nd} \mathrm{harmonic}$ provides $\sim 750 \mathrm{~mJ} /$ pulse at $10 \mathrm{~Hz}$. For OH or fuel excitation, the dye laser uses Rhodamine 590 (R-590) dye, producing pulses of $180 \mathrm{~mJ}$ at $564 \mathrm{~nm}$. In order to achieve the shorter UV wavelengths necessary for exciting NO electronic absorption transitions, an 80 percent R-590 dye solution was mixed with a 20 percent R-610 dye solution. The UV excitation wavelengths used had bandwidths of $1.0 \mathrm{~cm}^{-1}$, 
as measured by a Burleigh pulsed UV wavemeter. The UV light was separated from the residual dye or fundamental light output by a Pellin-Broca prism. The desired transition was verified by directing the laser beam through the flame of a Bunsen burner at atmospheric pressure for $\mathrm{OH}$, or a high pressure vessel containing $250 \mathrm{ppm}$ of $\mathrm{NO}$, and observing the fluorescence with a photomultiplier boxcaraverager system.

\section{Detectors}

The detectors used are Princeton Instruments gated, intensified CCD (ICCD) cameras with an array size of $384 \times 576$ pixels. The camera intensifier is synchronously triggered with the laser pulse through either a Princeton Instruments FG-100 or an FG-200 pulse generator. A Princeton Instruments ST-100 detector controller was used to gate the camera for typical times of $75 \mathrm{~ns}$.

The fluorescence signal normal to the incident excitation sheet was collected through a Nikon $105 \mathrm{~mm}$ f/4.5 UV Nikkor lens. Princeton Instrument's WinView softwarewas used to acquire the ICCD images. Two filtering schemes were used to collect $\mathrm{OH}(0,0)$ and $(1,1)$ band fluorescence and block scattered light. The first used a $2 \mathrm{~mm}$ thick WG-305 Schott glass filter in combination with a $1 \mathrm{~mm}$ thick Schott UG-11 bandpass filter. The UG-11 colored glass filter passes a peak wavelength of $340 \mathrm{~nm}$ and has bandpass from 245 to $410 \mathrm{~nm}$. The pair transmits $\sim 56$ percent of the incident radiation in the band between 310 and $320 \mathrm{~nm}$. The bandpass filter also passes light above $650 \mathrm{~nm}$ and has a peak transmittance at $720 \mathrm{~nm}$ of 27 percent. The second filter set used a combination of a WG-305 Schott glass filter $(2 \mathrm{~mm})$ and a narrow band interference filter from Andover Corp. \#313FS10-50, with a peak transmitt-ance of 16 percent at a wavelength of $315 \mathrm{~nm}$ and FWHM of $10.6 \mathrm{~nm}$. For NO detection, a narrow band interference filter centered at $238 \mathrm{~nm}$ with a FWHM of $8 \mathrm{~nm}$ was used. Its peak transmittance is 10 percent.

\section{Complicating Factors}

The following are the major issues which were found to increase the complexity of the OH PLIF technique beyond what is typically encountered using a small benchtop arrangement. We also discuss techniques used to mitigate problems caused by these complexities.

\section{Test Hardware}

Among the factors that contribute to the complex nature of these experiments compared to bench-scale atmospheric burners are rig growth, vibration, physical access and the rapid turnover of experimental hardware.

Each rig experiences axial growth as a result primarily of increased temperature. The effect is a change in position of the windows and fuel injectors relative to the incident laser sheets and imaging cameras. The rig displacement begins with the onset of preheated air and increases dramatically after lightoff. We have seen movement of up to $5 \mathrm{~mm}$, which is 13 percent of the window width. In order to compensate for the displacement, we track the shift by directing a helium-neon alignment laser toward a fixed point on the test rig, and observing the distance spanned on a scale attached to the rig. The laser sheet and cameras are then moved to compensate using traversing stages.

Rig vibration can also be a problem if it creates "enough" uncertainty in the spatial location of the probe. Fortunately, vibration has not been a problem for either test rig. Accelerometer measurements showed a near-zero amplitude of the optical system supports compared to test rig vibration. Had we found a large transverse amplitude, the most direct method of compensation would be to physically couple the detection hardware to the rig.

For safety reasons in this high pressure, high temperature facility, physical access to the test cell is restricted during tests. Therefore, all optical systems must be operated remotely; we monitor that operation with video cameras. We must ensure that all systems are operable before the test rig is checked out and that supplies of expendables such as the $\mathrm{N}_{2}$ used for detector cooling are sufficient to last for 12 to $14 \mathrm{hr}$. That time includes optical systems checkout, test rig warm-up, testing, and cooldown.

Finally, because of rigid test schedules, operations in the facility do not offer the opportunity for repeated test runs using the same test hardware. Such operations emphasize the fact that the objective of the tests is to diagnose the fuel injector hardware, rather than to develop laser diagnostic methods. This imposes constraints on refining the measurement methodology for any specific fuel injector under study. For example, the presence of liquid fuel in the measurement region requires a different approach than injectors for which the fuel is completely vaporized. The degree of fuel vaporization in the measurement zone varies depending on the test conditions within a given test run, and may not be known a priori. An additional variable is the injector geometry and its impact on fuel distribution and flow field swirl. Nonuniform fuel distributions have been observed during tests as well as large spray cone angles which deposit fuel on the combustor windows during ignition. Due to the variety of hardware that is tested, such problems cannot always be anticipated and compensated for before each test, which adds to the complexity of analyzing the data.

\section{Optical Systems}

The primary complicating factors for these optical systems result from the logistics of conveying the laser probe to the test hardware. Other issues include 
window cleanliness, window cooling and window structural integrity.

Figure 2 shows a schematic diagram of the principal optical components used for PLIF measurements. The key elements for wavelength generation and selection and fluorescence detection are shown. The beam transport system, which delivers the laser beam from the laser room to the test rig, is sketched in Figure 3. The beam transport system consists of remotely-controlled mirrors and traversing stages that allow positioning of the laser sheet and cameras; it provides a way to make minor corrections in position (e.g., to correct for axial test rig growth) and a mechanism to traverse the laser sheet across the test section in order to generate three-dimensional information.

Beam alignment is monitored through the use of video cameras to observe the beam location on key mirrors. By covering each mirror mount with white paper, which visibly fluoresces when the laser beam strikes it, we can determine the laser beam position and correct it if required.

The laser beam is usually allowed to expand freely through the beam transport system (divergence $\approx 5 \mathrm{mrad}$ ). The beam is formed into a sheet by passing it through a square cylindrical lens, $50.8 \mathrm{~mm} / \mathrm{side}$, with focal length $3000 \mathrm{~mm}$, resulting in a sheet with approximate dimensions, dependent on beam travel, of $25 \times 0.3 \mathrm{~mm}$.

The approximate path lengths from the laser to the flame tube and sector test stands are 18 and $25.5 \mathrm{~m}$. This tremendous lever arm has a significant effect when changing the laser wavelength. We typically compensate for this shift by targeting the beam on a fixed point near the test rig, and correcting the drift by adjusting the final turning mirror in the laser room.

The degree of window cleanliness can affect the energy distribution of the laser sheet and block transmission of the fluorescence signal to the camera. Soot formation and buildup is the greatest source of degradation of both the laser input and fluorescence detection windows. Soot typically accumulates only when the inlet temperature is relatively cool $(<550 \mathrm{~K})$ and fuel is incident on the window; fortunately, this happens rarely. Figure 4 shows a comparison of images resultant through a sooty window and a clean window. The image on the left in Figure 4 was acquired under conditions when soot built up on the top half of the collection window; the image on the right was taken under conditions when soot did not accumulate on the windows. We find that the incident UV laser sheet cleans the window as it passes through, so there is little or no soot on the entry window. Cleaning the observation window is accomplished by setting up a second beam path and traversing a laser sheet across the dirty window(s). This works well to clean the windows, but since one cannot take data and clean the windows simultaneously, soot may build up on the windows between cleanings.
Molecular Spectra and Imaging

Imaging individual fluorescent species within the combustion flowfields typical of those examined in this study presents numerous challenges. These obstacles include such phenomena as pressure-induced line broadening and fluorescence quenching effects, and competitive fluorescent processes arising from other molecular species such as oxygen or from constituents of the kerosine fuel. Other sources of interference may include laser light scattering, flame emissions, or flame tube wall luminescence. The latter obstacles can be eliminated or greatly suppressed by adjusting the timing of the image intensifier gate or by implementing selective filtering techniques. Other potential problems related to incident laser sheet attenuation can be overcome by a judicious selection of the proper laser excitation wavelengths. As in all high pressure studies, a decrease in fluorescence signals is observed at elevated pressure due to quenching; and a decrease in the overlap integral is resultant from the reduced absorption coefficient. Despite these factors, no impediments were found that precluded the accumulation of PLIF images at pressures approaching $20 \mathrm{~atm}$.

\section{$\underline{\mathrm{OH}}$ imaging challenges}

The greatest challenge to $\mathrm{OH}$ imaging has been spectral competition with fluorescence of the fuel (or, more accurately, certain fuel constituents). Fuel fluorescence is not a factor when imaging far enough downstream of the fuel injector, in the burnt gases region. ${ }^{13,14}$ However, the need to understand the physics of the fuel/air mixing and fuel vaporization processes mandates imaging near the fuel injector exit plane. Jet-A, JP-5, and similar aviation fuels typically contain a small percentage of naphthalene and its derivatives. ${ }^{15}$ These polycyclic aromatic hydrocarbons (PAH) are broadband absorbers and emitters which absorb and emit in the same wavelength region as $\mathrm{OH}$. Figure 5 shows the absorption spectrum of a $1 \times 10^{-4}$ molar solution of JP-5 in isooctane. The weaker secondary absorption feature centered at $271 \mathrm{~nm}$ is attributable to the PAH. For comparison, Figure 6 presents the absorption and emission spectra of a $7 \times 10^{-3}$ molar concentration of naphthalene in cyclohexane. ${ }^{16}$ Naphthalene absorbs strongly from 255 to $290 \mathrm{~nm}$ and emits very strongly from 320 to $350 \mathrm{~nm}$.

Previous studies conducted at NASA Lewis Research Center using JP-5-fueled single cup injectors demonstrated the value of carefully selecting the laser excitation wavelength. ${ }^{13}$ Flows from these types of injectors were found invariably to be optically thick, resulting in certain $\mathrm{OH}(1,0)$ excitation wavelengths to be subject to a marked increase in incident laser sheet attenuation than others. 
Figure 7 shows the fluorescence excitation spectrum of $\mathrm{OH}$ at $1 \mathrm{~atm}$ (top) and $14.3 \mathrm{~atm}$ (bottom) and highlights the effects of pressure-induced line broadening. Both spectra used the WG-305/UG-11 filter combination. Even at $14.3 \mathrm{~atm}$, line spacing in the $\mathrm{OH} \mathrm{A}^{2} \Sigma^{+} \leftarrow \mathrm{X}^{2} \Pi(1,0)$ band is sufficiently large so that isolated features exist and are accessible for spectroscopic species evaluation purposes.

\section{NO imaging challenges}

As in the case of $\mathrm{OH}$, the $\mathrm{NO}(0,0) \mathrm{A}^{2} \Sigma^{+} \leftarrow \mathrm{X}^{2} \Pi$ band experiences line broadening effects at elevated pressure. Even though this effect is $\sim 3$ times that observed for $\mathrm{OH}$, there still exist numerous lines sufficiently isolated from adjacent lines to permit NO imaging. The main detriment to imaging $\mathrm{NO}$ at elevated pressure and temperature is the competing fluorescence arising from the SchumannRunge bands $\left(\mathrm{B}^{3} \Sigma_{u} \leftarrow \mathrm{X}^{3} \Sigma_{g} ; 175\right.$ to $250 \mathrm{~nm}$ ) of molecular oxygen. These transitions overlay the spectral region in which $\mathrm{NO}$ absorbs and emits, and increase in strength with rising temperature. However, recent studies have shown that NO LIF and PLIF at high pressure can succeed, through various approaches which include subtracting the $\mathrm{O}_{2}$ background, doping the flame with NO, selective narrow-band filtering, and judicious laserline selection. ${ }^{17-20}$

\section{Fuel imaging challenges}

The fluorescence of the fuel and/or its constituent species constitutes the major interference encountered in this study. However there is a lack of spectroscopic data on kerosine-based aviation fuels. A significant amount of work is necessary to gain insight into the complex behavior of multicomponent fuels, including liquid and vapor compositions as functions of combustor pressure, temperature, and fuel droplet residence time. Obtaining this information is further complicated since the critical point for a multicomponent fuel is not well-defined, so the properties and phase of the fuel are not known even for a nonreacting case.

\section{$\underline{\text { Image Analysis }}$}

Standard procedures for handling images include subtracting the background, removing random noise spikes, and determining the image magnification. One additional procedure that is under consideration is correction for laser sheet energy nonuniformity.

The image magnification and the format for display are determined by the use of a calibration card, placed at the zero position inside the combustor. The card has a calibrated scale with which to determine the magnification and marks indicating the direction of travel of both the bulk combustor flow and the direction of laser beam travel. These card images are then used to orient images for display according to a standard coordinate system. The calibration card allows us to correct images for different camera positions and variations in camera array readout.

Correction of images for laser beam nonuniformity requires knowledge of both the beam intensity profile and its location within each image. We have tried splitting off a small portion of the input laser sheet with a thin quartz plate and directing it to another camera, using it as a beam profiler. Two lines (profiles) were observed corresponding to the primary reflection and a secondary reflection from the back surface of the quartz plate. The secondary reflection imposes only one of the problems associated with using the beam profiler to correct an image for laser beam energy nonuniformity. Use of a thicker plate would serve to separate the reflections. Among the other problems are handling the different camera magnifications, determining accurately the axial alignment of the PLIF image with the profiler image, and triggering and timing issues if different types of cameras are used. There is also uncertainty in the correlation between the beam profile and the actual energy distribution. This uncertainty is associated with the cleanliness of the input window as a test progresses. Another problem that we have encountered is that we have not yet determined a method that appropriately deals with abrupt changes in intensity, which typically occur at the boundary of the beam.

The procedure for removing noise spikes (high signal) employs the use of a user-defined threshold for the difference, $\Delta$, between the high pixel value and the next highest in the image. Then, for any pixel having $\Delta$ above the threshold, its value is assigned the value of the next highest pixel in its histogram neighborhood, and $\Delta$ is recalculated. The process is repeated until the difference is below the threshold.

Intra-image scaling is used for display to highlight the low-level features within an image. The user defines a subregion within the overall image. The small region is then scaled based on its maximum and minimum values (self-scaled). The outside region is then scaled so that its maximum value is the same as the maximum value of the subregion.

\section{Discussion}

We examine four fuel injector configurations, two in the sector and two in the flame tube, each designed for fuel-lean operation. Although the overall equivalence ratio ranges from 0.3 to 0.7 , the local equivalence ratio can vary greatly. Because in most cases we probe immediately downstream of a fuel injector exit, the local equivalence ratio can be greater than one.

The figures presented are not corrected for laser sheet energy nonuniformities for many of the reasons noted in the section describing the major complicating factors. 
The color bar consists of 25 colors, plus black (low) and white (high). Each color accounts for $\sim 10$ counts (4 percent) in the linear span from 0 to 255 counts of signal. Black represents the lowest 2 counts in signal, white represents the highest two signal values of 254 and 255.

The coordinates are defined as follows and obey the right-hand rule. $\mathrm{z}$ is the axial direction with higher numbers farther downstream. $\mathrm{x}$ is the azimuthal (horizontal) direction with positive $\mathrm{x}$ to the left when looking downstream. $y$ is the radial (vertical) coordinate with positive numbers above the zero position. The zero position for $\mathrm{z}$ is the injector exit plane, or the top dome exit plane in the sector; for $\mathrm{x}$, zero coincides with the rig centerline; and for $y$, zero is the bottom of the top dome in the sector and coincides with the rig centerline in the flame tube. Figure 8 shows a sketch of the image orientation and coordinate system used.

Single-shot images capture "instantaneous" snapshots of the flow, allowing analysis of turbulent environments; multiple shots can render a good representation of the average characteristics of the flow. The decision about which imaging technique to use may depend on the goals of the research, or the choice may be dictated by circumstance. The "perfect" option is to take many singleshot images, then average in post-processing. We have found for the present work that 25 averaged fluorescence events is adequate to represent the average flow structure for the test hardware studied. These average characteristics are the most useful for hardware designers and combustor modeling. Unfortnately, taking many single-shot exposures is time-consuming, especially during the time allotted (typically $5 \mathrm{hr}$, maximum) to complete a test matrix. The test matrix may include taking data (at many spatial locations) at several temperatures, pressures, equivalence ratios, and flow rates. Operationally, the time to get to each test condition and traversing the laser and detectors across the flow can fill a lot of that time. There is also always the potential for premature shutdown due to a mechanical failure within the test facility, which provides incentive to take data quickly.

Given a typical test run in our facility, we find that the most efficient way to obtain average images is to integrate the fluorescence events on the detector array, producing "on-chip averages". The time required to take a full frame image consists of the exposure time; the shutter compensation time (a constant), made up of the times to open and to close the shutter; and the CCD readout time, which is set for a given detector array size and the analogto-digital converter rate. In addition, for each image taken, we visually verify that there are no obvious flaws in the image before taking another image. As an example of the time saved by on-chip averaging, consider averaging fifty fluorescence events. A single-shot image takes about 2.2 seconds to acquire; therefore, fifty such shots require 110 seconds. A fifty-shot on-chip average takes 7.2 seconds, which is more than fifteen times shorter than the acquisition time for fifty individual images.

The broadband filter set was initially selected for $\mathrm{OH}$ PLIF because of its greater light collection efficiency over narrowband filtering and several broadband filtering approaches have been effective in other flame studies. ${ }^{21,22}$ The presence of PAH (presumed in this effort to be predominantly naphthalene) was not initially considered. The transmission curves, derived from product specifications and published spectra, are shown in Figure 9 for broadband and narrowband detection. The broadband set transmits over five times more light than the narrowband set at $315 \mathrm{~nm}$ (the peak transmission wavelength of the inter-ference filter). One (potential) drawback is that the UG-11 filter transmits broadly between 245 and $410 \mathrm{~nm}$, with a peak transmittance of 84 percent at $330 \mathrm{~nm}$. In considering the PAH interferences to the $\mathrm{OH}$ fluorescence signal, the broad transmission must be taken into account. Using the naphthalene curve of Figure 6 as an example, we find that at $330 \mathrm{~nm}$ the broadband filter will transmit over 20 times more light than will the narrowband filter at $315 \mathrm{~nm}$, when the relative photon intensities are considered. The UG-11 filter also transmits light in the red to near infrared.

Figure 10 shows a comparison between the broadband (top) and narrowband (bottom) detection schemes used in the sector test rig. The flow travels from left to right. The images were taken using two cameras looking through opposite windows at approximately the same time (the cameras were synchronized to the laser but not synchronized to one another). Each image is composed of 100 shots integrated on-chip. Resonant $\mathrm{OH}$ using the $\mathrm{Q}_{2}(7)$ excitation transition is shown on the same scale with its corresponding nonresonant-OH image for each detection method. Beside each pair is its resultant image when the nonresonant signal is subtracted from the resonant signal; additionally, these images are presented again, but independently-scaled. The upper 25 percent of each image is directly downstream of the exit of a lean premixed prevaporized injector; therefore, a large amount of fuel is present. The next 25 percent is in the expected recirculation region between the top and middle domes. The lower half of the images is $\sim 5 \mathrm{~cm}$ downstream of the center dome (using partially-premixed injectors), where only $\mathrm{OH}$ is expected. The small indentation on the left and near the bottom of the narrowband images is most likely due to deposits on that window. As seen in Figure 10, the results of this comparison are obvious and profound. In the broadband case, there is strong signal in both the resonant and nonresonant images that we attribute to fuel PAH. That region of high signal is located immediately downstream of a fuel injector. 
We found in the narrowband images that the highest nonresonant signal is typically 5 percent of the resonantly excited signal, and that the region of high signal in the nonresonant image is not colocated with the region of high signal in the resonant image. For broadband detection, the signal levels within the $\mathrm{OH}$ resonantly and nonresonantly excited images were comparable. These factors indicate that the narrowband set of filters does a fairly adequate job of eliminating PAH interferences.

There is little observable scatter of the incident laser sheet from the dome or other hardware when using narrow-band detection; while this is advantageous in one sense, the drawback is that it becomes more difficult to determine the location of the images with respect to the dome or fuel injector exit. The narrowband scheme is effective at eliminating (PAH), but is not perfect. This can probably be improved upon by using a narrower interference filter, on the order of 2 to $5 \mathrm{~nm}$ FWHM. For broadband detection, one cannot optimize the dynamic range for $\mathrm{OH}$ without saturating the detector when $\mathrm{PAH}$ signals are encountered. However, one can easily image the fuel only, especially when the laser is tuned away from an $\mathrm{OH}$ excitation transition. Another advantage in this case is the ability to easily determine spatial distances from the injector exit because the dome (through filter transmission in the red and near IR) is a well-defined marker. We presently find the current 10 to $12 \mathrm{~nm} \mathrm{FWHM}$ interference filter to be useful in imaging $\mathrm{OH}$ when tuned to a resonant transition and good for imaging the fuel, via $\mathrm{PAH}$, when tuned to a nonresonant $\mathrm{OH}$ wavelength.

Although NO has known spectral interferences such as competition from Shumann-Runge $\mathrm{O}_{2}$ bands, as a stable species it allows calibration of the detector through seeding known amounts into the flow. This method has been used successfully in high pressure flames. ${ }^{19}$ This is the procedure used in the sector test rig. We found a linear response to seeding the flow with up to $200 \mathrm{ppm}$ prior to combustion; however, after burning was initiated, we found that in the NO-doped flame the signal dropped by about 15 percent compared to the signal obtained without dopant. Although we successfully imaged NO in the flame (without seed) and obtained qualitative agreement with gas sampling measurements, ${ }^{20}$ it is apparent that some reaction(s) is consuming the NO that was seeded and possibly impeding its formation in the flame. These processes are unknown and require further study in order to make quantitative images of NO.

Figures 11 and 12 show fuel PLIF end views (flow travels out of the page) of three individual fuel injectors. The fluorescence signal was detected through the use of the narrowband filter set for OH PLIF described earlier, with images composed of 50 shots averaged on the detector.
The composite images were generated using software that is generally used for computational fluid dynamics computations. Our grid dimensions and spacing are determined by the camera pixel size and magnification, and by the laser beam traverse interval. Our traverse interval is generally from $\pm 20 \mathrm{~mm}$, with a step size of 1 or $2 \mathrm{~mm}$. Thus, using vertically implemented laser sheets as an example, given a $1 \mathrm{~mm}$ step size, a stack of 41 images is incorporated into the grid and defines the range in the $x$ direction. Camera magnification defines the $y$ dimension and sets the maximum range in $\mathrm{z}$. The actual relevant $\mathrm{z}$ dimension is dictated by the width of the laser sheet. For example, given a $25 \mathrm{~mm}$ wide laser sheet and a camera magnification factor of 9 pixels $/ \mathrm{mm}$, a $576 \times 384$ pixel array is transformed to $\mathrm{y}=64 \mathrm{~mm}$ by $\mathrm{z}=42.7 \mathrm{~mm}$, but the $\mathrm{z}$ dimension of interest is really $25 \mathrm{~mm}$. The images of Figures 10 and 11 are then constructed by extrapolation using the available data points to form smoothly colored polygons. We have also placed our images within existing computer-aided design or computational fluid dynamics grids that represent the actual hardware, thus enabling us to visualize the relationship between the images and the test hardware.

In order to ease the processing burden of incorporating $576 \times 384$ pixel images into the array, by pixel binning we reduced the number of pixels by a factor of 8 to produce $72 \times 48$ pixel images. Alternatively, we can bin pixels on the camera detector as data is being collected. Which method to choose is determined by the strength of the fluorescence signal. Weak signals often require pixel binning; very strong signals saturate the detector when binning is employed, so the camera detector is not binned for these strong signals.

Figure 11 shows the fuel distribution for three fuel injectors at $\sim 10 \mathrm{~mm}$ from their respective exit planes. Using composite views such as these simplifies the effort to determine whether an injector produces a symmetric fuel distribution (as those shown were designed to produce). Composites can be produced for any species we choose to measure.

Figure 12 shows the progression of the fuel distribution for one injector as it travels downstream from the fuel injector. From images such as these, we can deduce the spray angle by projecting the loci of peak signals; by comparing the signal per unit area, we can make statements about the degree to which the fuel has been consumed.

Further study is required to determine the effects of temperature and phase on the fuel fluorescence signal. We have seen distinctly nonlinear trends in signal during tests, but to date have been unable to resolve all factors that affect the signal. In particular, a well-controlled parametric study using dispersed fluorescence that includes temperature, pressure, and phase should be conducted. 
We have discussed the major issues encountered to date in PLIF imaging of $\mathrm{OH}$ and $\mathrm{NO}$ in a realistic aeropropulsion gas turbine combustion environment. We described the limitations imposed by operating within a physically inaccessible test cell and the barriers encountered in performing advanced diagnostic techniques on diverse test hardware; we then provided some solutions that have succeeded in minimizing those limitations. We saw that fuel, via PAH spectral interferences, is the major obstacle in obtaining interpretable $\mathrm{OH}$ images; however, narrowband filtering was found to negate most of these interferences. Further reduction of the PAH fluorescence can probably be achieved through the use of a much narrower interference filter, or perhaps by imaging only the shorter wavelength $\mathrm{OH}(0,0)$ bands between 306 and $310 \mathrm{~nm}$ that are more isolated from the fuel emission region.

Alternatively, it is serendipitous that wavelengths which excite $\mathrm{OH}$ also excite fuel because it provides a convenient method to look at fuel patternation in the actual operating regime for which the injectors are designed. Detailed knowledge of fuel patternation is critical to the success of next generation combustor development. The optically accessible test rigs at NASA Lewis provide the singular opportunity to observe and to optically probe this strategic parameter at actual conditions. It is important to note that further study is essential to understand the fuel vaporization dynamics and the spectral dependencies on temperature and pressure if we are to attempt to quantify the fuel fluorescence.

To that end, preliminary studies have been initiated to evaluate the liquid fuel-rich region immediately downstream of the fuel injectors via Mie scattering and Phase Doppler Anemometry. Other work is also planned that will examine this region for other molecular species as well as interrogating the feasibility of shorter interference bandpass filters.

\section{Acknowledgments}

The authors wish to thank the more than 15 other people who make it possible to perform our experiments: the operations engineers; the mechanical, electrical, and electronics technicians; the calibration lab personnel; and fellow research engineers; without whom our "complicating factors" would become "show-stoppers."
1. Allen, M.G. and Hanson R.K., "Digital Imaging of Species Concentration Fields in Spray Flames," Twenty-first Symposium (International) on Combustion, The Combustion Institute, 1986, pp. 1755-1762.

2. Allen, M.G., McManus, K.R., and Sonnenfroh, D.M., "PLIF Imaging Measurements in High-Pressure Spray Flame Combustion," AIAA Paper No. 94-2913, 30th AIAA/ASME/SAE/ASEE Joint Propulsion Conference, July 1994.

3. Allen, M.G., McManus, K.R., and Sonnenfroh, D.M., "PLIF Imaging in Spray Flame Combustors at Elevated Pressure," AIAA Paper No. 95-0172,33rd Aerospace Sciences Meeting, Reno, Nevada, January 1995.

4. Battles, B.E., Seitzman, J.M., and Hanson, R.K., "Quantitative Planar Laser-Induced Fluorescence Imaging of Radical Species in High Pressure Flames," AIAA Paper No. 94-0229, 32nd Aerospace Sciences Meeting, Reno, NV, January 1994.

5. DiRosa, M.D., Klavuhn, K.G., and Hanson, R.K., "PLIF Imaging of $\mathrm{NO}$ and $\mathrm{O}_{2}$ in High-Pressure Flames," Optical Techniques in Fluid, Thermal, and Combustion Flow, Soyoung Cha, James D. Trolinger, Editors, Proc. SPIE 2546, July 1995, pp. 509-518.

6. Neij, H. and Aldén, M., "Application of Two-Photon Laser-Induced Fluorescence for Visualization of Water Vapor in Combustion Enviornments," Applied Optics, Vol. 33, No. 27, 1994, pp. 6514-6523.

7. Suntz, R., Becker,H., Monkhouse, P., and Wolfrum, J., "Two Dimensional Visualization of the Flame Front in an inernal Combustion Engine by Laser-Induced Fluorescence of OH Radicals," Applied Physics B, Vol. 7, 1988, pp. 287-293.

8. Schipperijn, F.W., Nagasaka, R., Sawyer, R.F., and Green, R.M., "Imaging of Engine Flow and Combustion Processes," SAE Paper 881631, 1988.

9. Felton, P.G., Mantzaras, J., Bomse, D.S., and Woodin, R.L., "Initial Two-Dimensional Laser Induced Fluorescence Measurements of $\mathrm{OH}$ Radicals in an Internal Combustion Engine," SAE Paper 881633, 1988.

10. Andresen, P., Meijer, G., Schlüter, H., Voges, H., Koch, A., Hentschel, W., Oppermann, W., and Rothe, E., "Fluorescence Imaging Inside an Internal Combustion Engine Using Tunable Excimer Lasers," Applied Optics, Vol. 29, No. 16, 1990, p. 2392. 
11. Stepowski, D., Cessou, A., and Goix, P., "Flame Stabilization and $\mathrm{OH}$ Fluorescence Mapping of the Combustion Structures in the Near Field of a Spray Jet," Combustion and Flame, Vol. 99, 1994, pp. 516-522.

12. Versluis, M., Boogaarts, M., Klein-Douwel, R., ter Meulen, J.J., Meerts, W.L., and Meijer, G., "LaserInduced Fluorescence Imaging in a $100-\mathrm{kW}$ Natural Gas Flame," Applied Physics B, Vol. 55, 1992, pp. 164-170.

13. Locke, R.J., Hicks, Y.R., Anderson, R.C., and Ockunzzi, K.A., "OH Imaging in a Lean Burning High Pressure Combustor," AIAA Journal, Vol. 34, No. 3, 1996, pp. 622-624.

14. Hicks, Y.R., Locke, R.J., Anderson, R.C., and Ockunzzi, K.A., "Planar Imaging of Hydroxyl in a High Temperature, High Pressure Combustion Facility," Optical Techniques in Fluid, Thermal, and Combustion Flow, Soyoung Cha, James D. Trolinger, Editors, Proc. SPIE 2546, July 1995 pp. 465-476; NASA TM-107074, October 1995.

15. Coordinating Research Council, Inc., Handbook of Aviation Fuel Properties, CRC Report No. 530, Coordinating Research Council, 1983.

16. Berlman, I.B., Handbook of Fluorescence Spectra of Aromatic Molecules, 2ndEd., Academic Press, 1971.
17. Reisel, J.R., Partridge, W.P., and Laurendeau, N.M., "Transportability of a Laser-Induced Fluorescence Calibration for NO at High Pressure," J. Quant. Spectrosc. Radiat. Transfer, Vol. 53, No. 2, 1995, pp. 165-178.

18. Battles, B.E., "Quantitative Fluorescence Measurements of Nitric Oxide and the Hydroxyl Radical in High Pressure Methane Flames," Stanford University HTGL Report No. T-297, April 1994.

19. Reisel, J.R. and Laurendeau, N.M., "Laser-Induced Fluorescence Measurements and Modeling of Nitric Oxide in High-Pressure Premixed Flames," NASA CR-195404, December 1994.

20. Hicks, Y.R., Locke, R.J., Anderson, R.C., Ockunzzi, K.A., and Schock, H.J., "Planar Imaging of $\mathrm{OH}$ and $\mathrm{NO}$ in a High Temperature and Pressure Combustion Sector Rig," NASA TM-107344, October 1996.

21. Laurendeau, N.M. and Goldsmith, J.E.M., "Comparison of Hydroxyl Concentration Profiles using Five Laser-Induced Fluorescence Methods in a Lean Subatmospheric-Pressure $\mathrm{H}_{2} / \mathrm{O}_{2} /$ Ar Flame," Combust. Sci. and Tech., Vol. 63, 1989, pp. 139-152.

22. Battles, B.E. and Hanson, R.K., "Quantitative Fluorescence Measurements of the OH Radical in High Pressure Methane Flames," AIAA Paper No.92-2960, AIAA 23rd Plasmadynamics \& Lasers Conference, July 1992. 

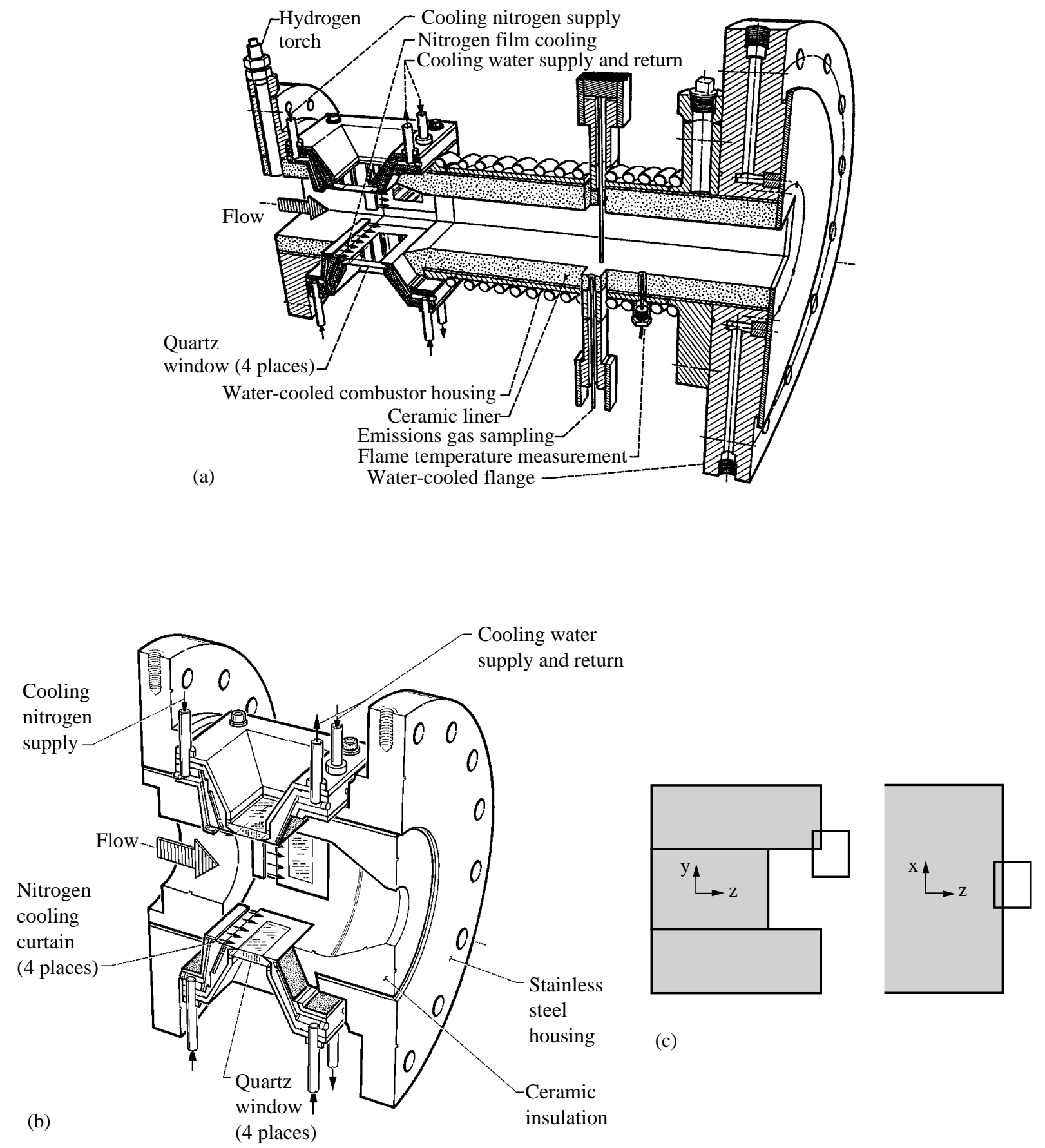

Figure 1.-Optically accessible test hardware. (a) Flame tube combustion shell with quartz window assemblies; (b) sector combustion shell, and; (c) arrangement of the three sector domes with respect to the windows along with the side view and top view. 


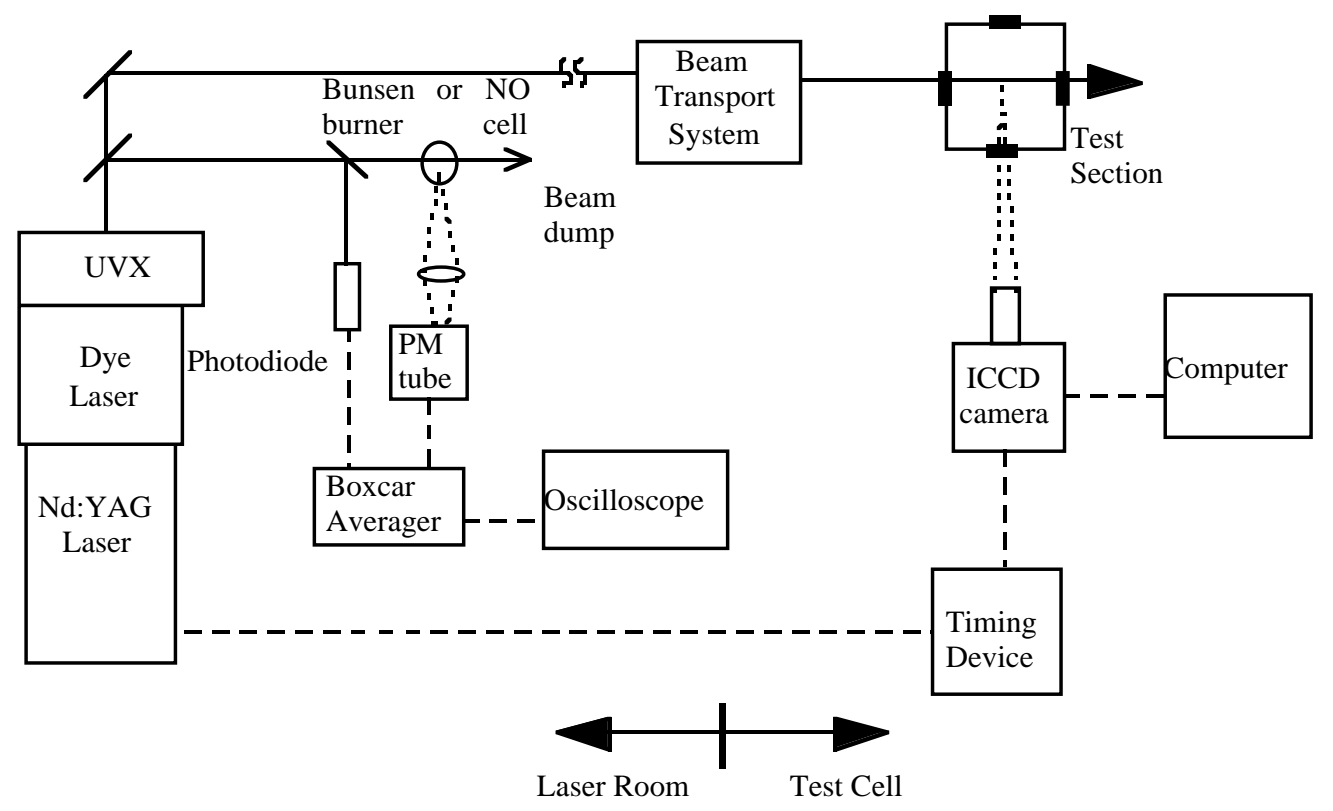

Figure 2.-Schematic diagram of optical apparatus for fluorescence measurements.

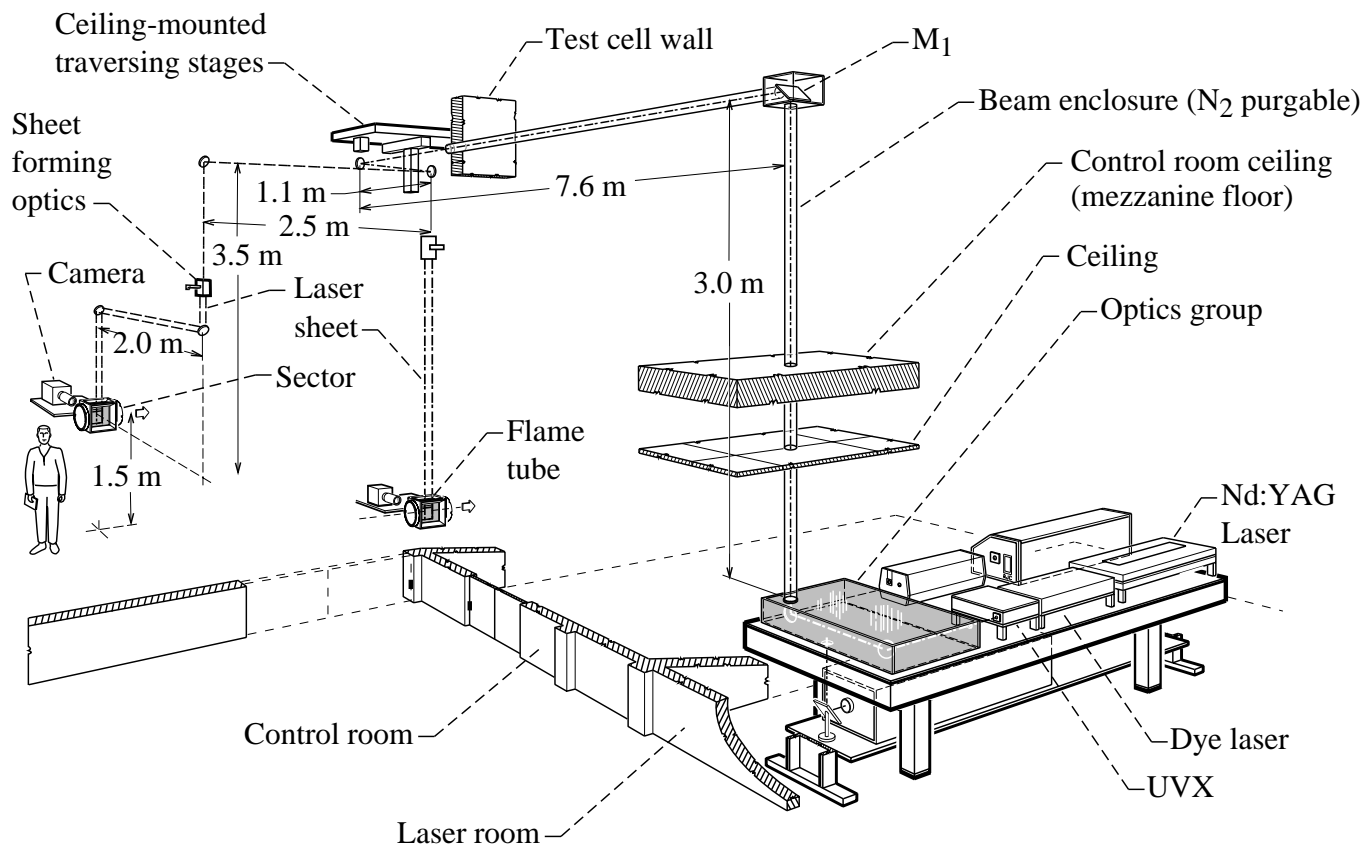

Figure 3.-Laser beam path to sector and flame tube test rigs. 


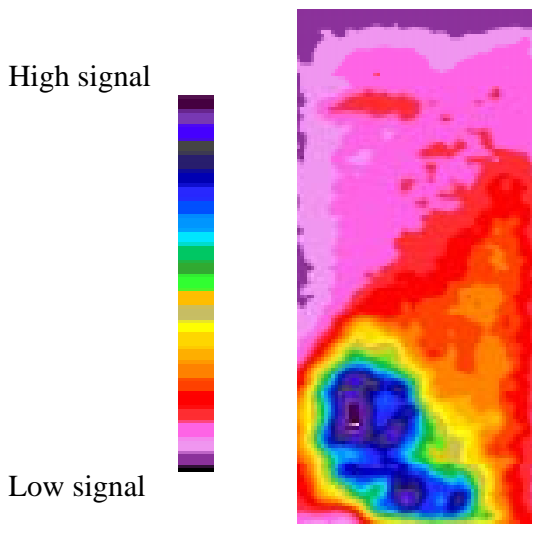

Window obscured by soot

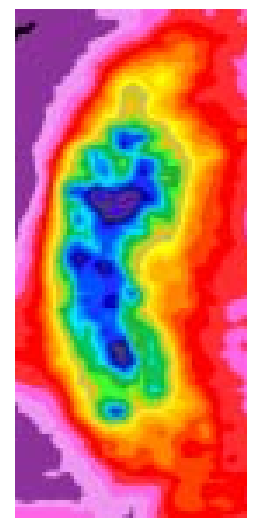

Clean window

Figure 4.-Comparison showing the effect of soot buildup on the fluorescence collection window.

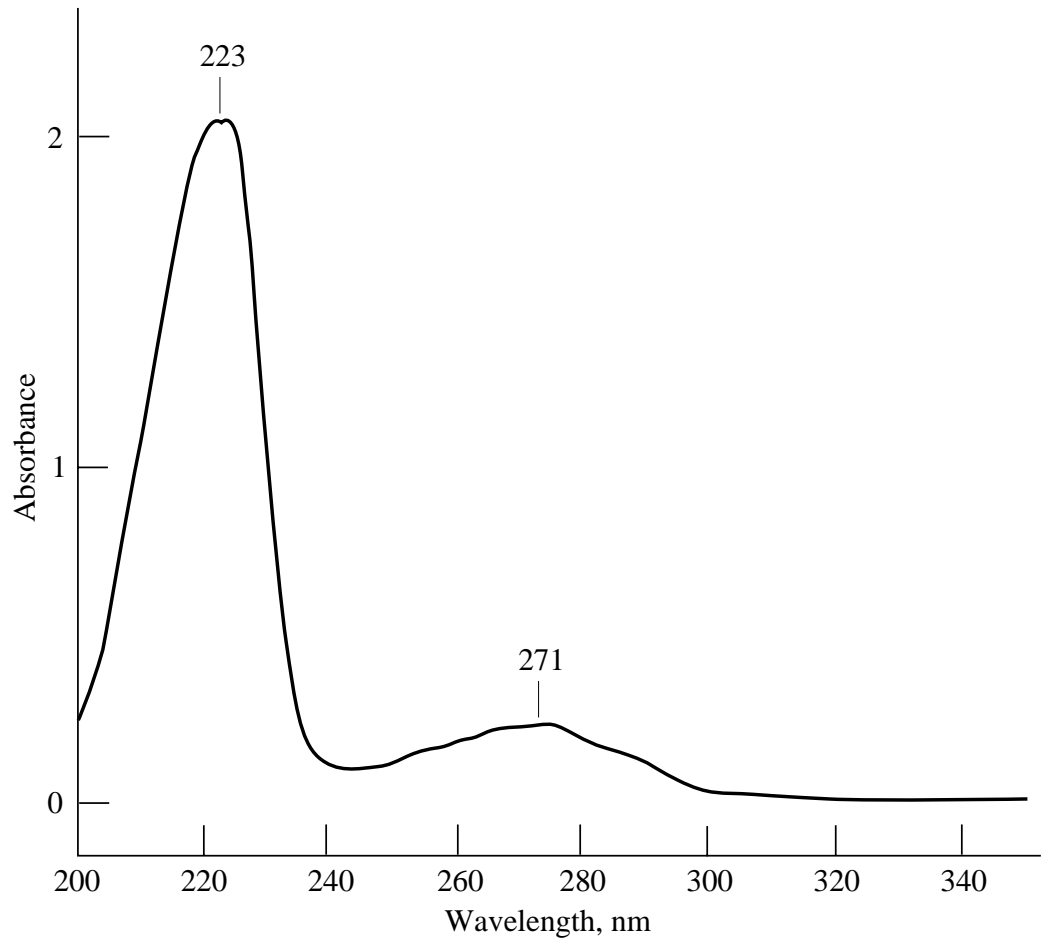

Figure 5.-Absorbance of JP5 in the range from $200 \mathrm{~nm}$ to $350 \mathrm{~nm} .1 \times 10^{-4}$ molar solution in isooctane. 


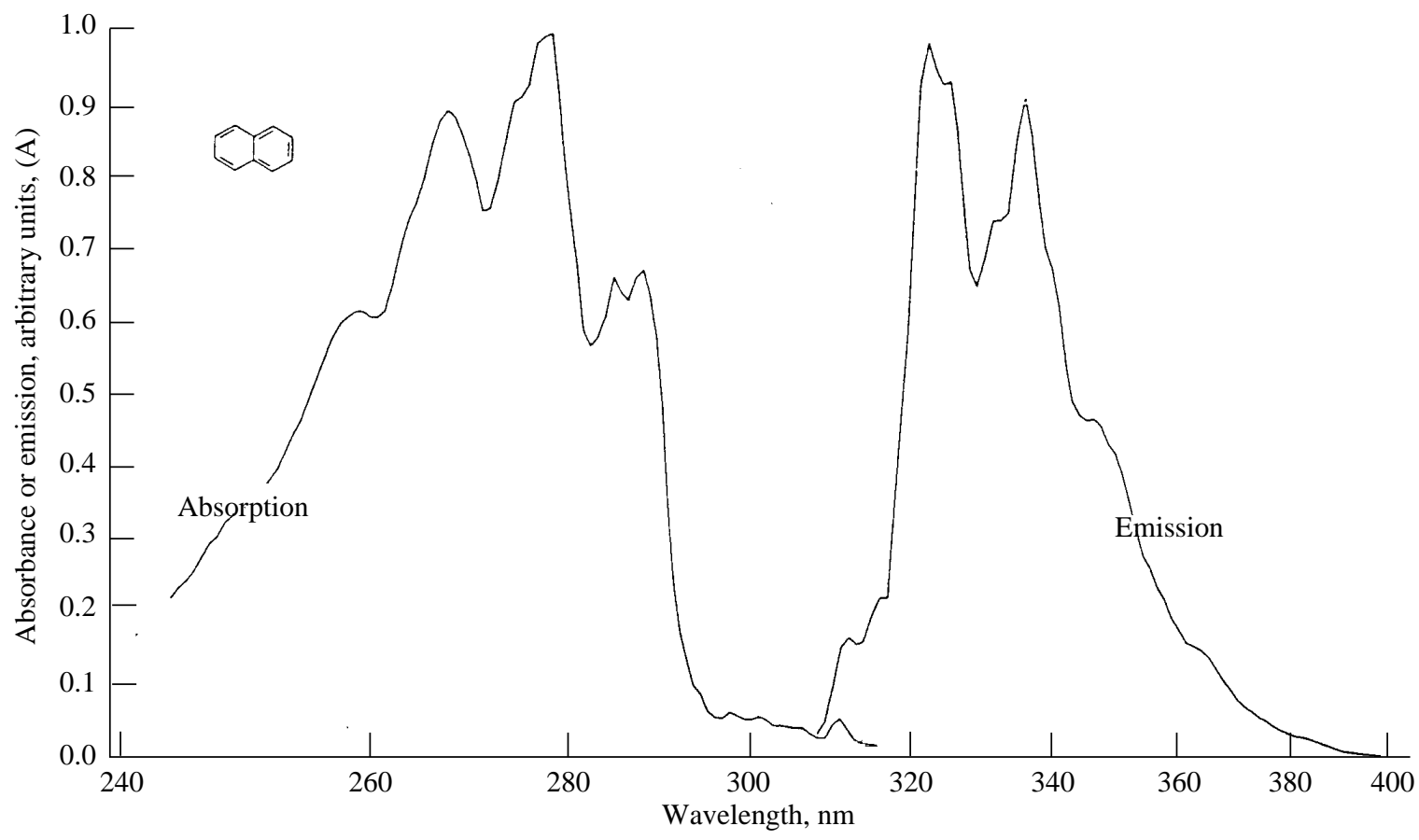

Figure 6.-Absorbance and emission of naphthalene in the range from $240 \mathrm{~nm}$ to $400 \mathrm{~nm}$. $7 \times 10^{-3}$ molar solution in cyclohexane. Laser excitation for emission spectrum is $265 \mathrm{~nm}$. Adapted from reference 16, graph 130c.
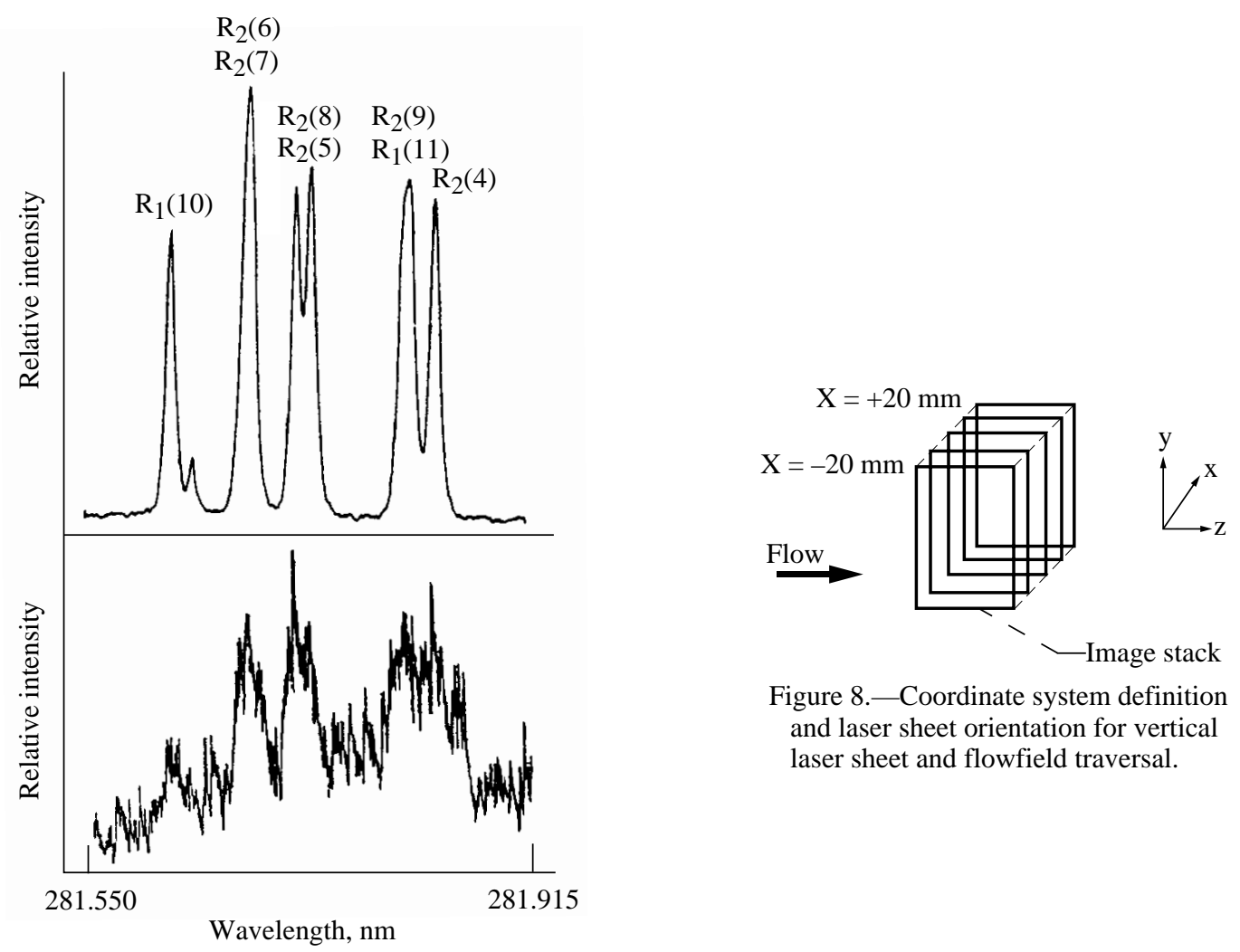

Figure 8.-Coordinate system definition and laser sheet orientation for vertical laser sheet and flowfield traversal.

Figure 7.-Effect of the combustion environment on the $\mathrm{OH}$ laser-induced fluorescence signal. Top: propane/air Bunsen burner flame at standard temperature and pressure. Bottom nonpremixed JP5/air flame at $14.3 \mathrm{~atm}$ and $800 \mathrm{~K}$ inlet temperature. 


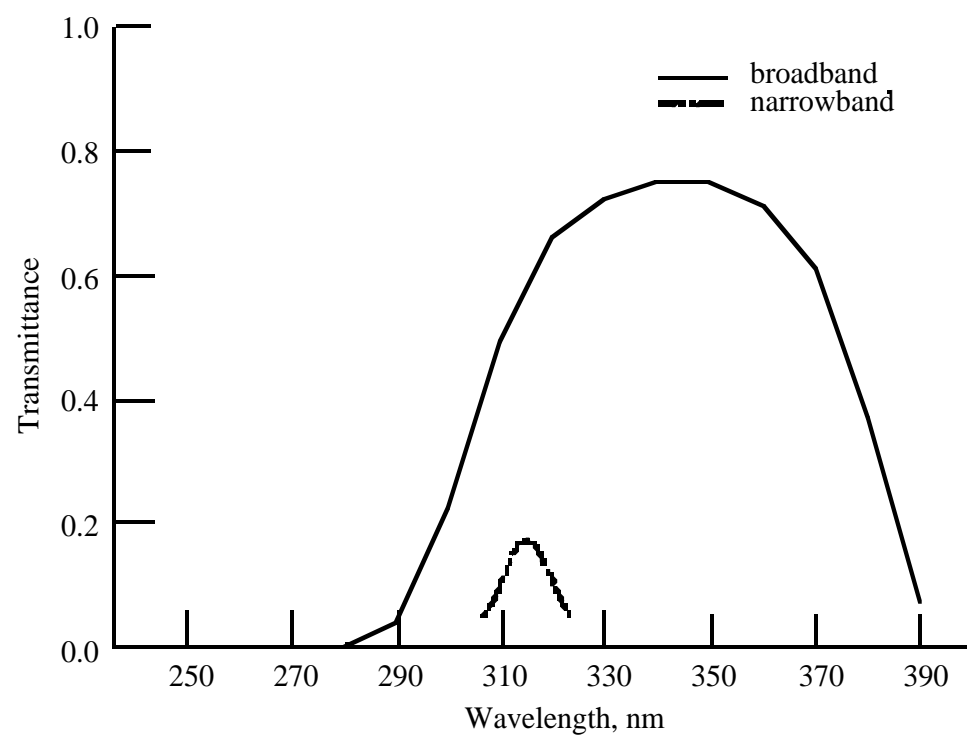

Figure 9.-Comparison between the transmittance of the broadband and narrowband filter sets used for fluorescence detection of the $\mathrm{OH}$ and $\mathrm{PAH}$ molecules.

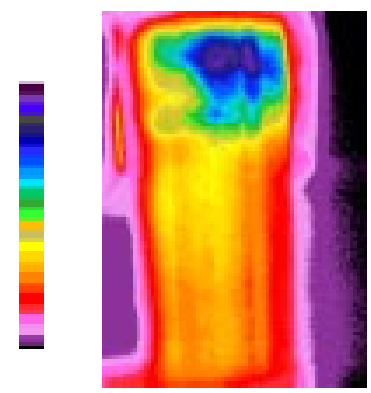

$\mathrm{OH}$ resonant

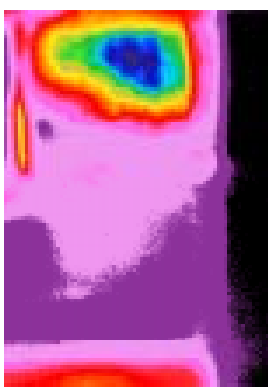

Non OH resonant

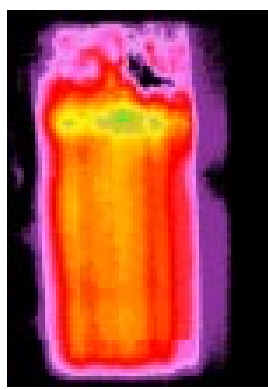

Resonant - non-resonant Same scale

Broadband Detection

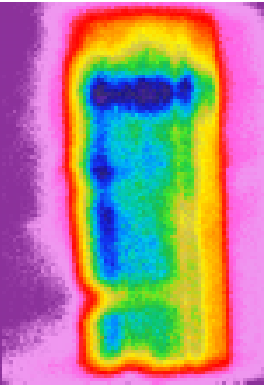

$\mathrm{OH}$ resonant

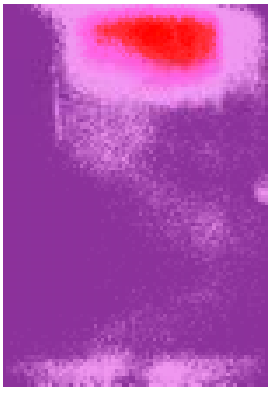

Non $\mathrm{OH}$ resonant

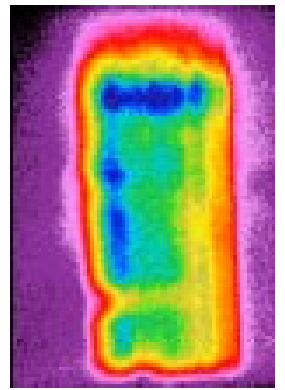

Resonant - non-resonant

Same scale

Narrowband Detection

Figure 10.-A comparison of images obtained using narrowband and broadband detection for $\mathrm{OH}$. 

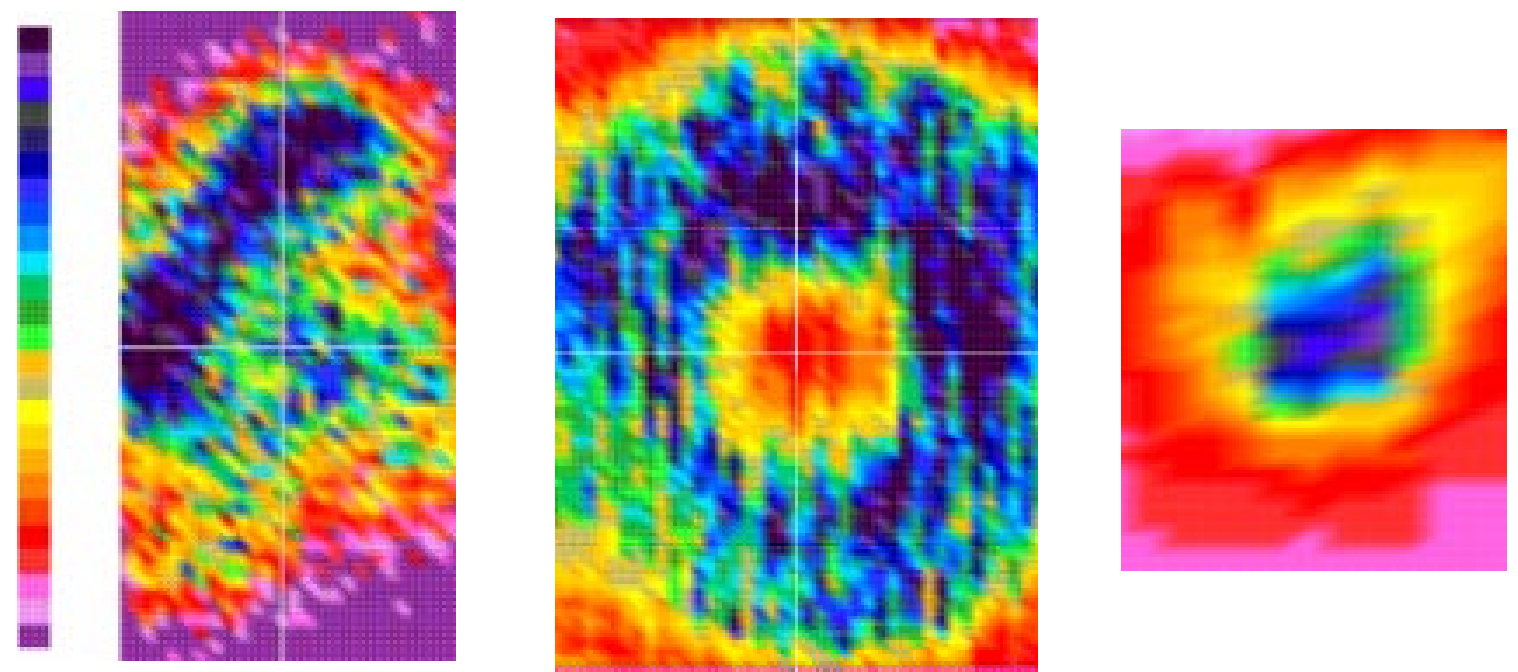

Figure 11.-Fuel patternation via fluorescence approximately $10 \mathrm{~mm}$ downstream from three concept lean-burn injectors (various $\mathrm{T}_{\text {in }}, \mathrm{P}_{\mathrm{in},}$ and $\phi$ ).

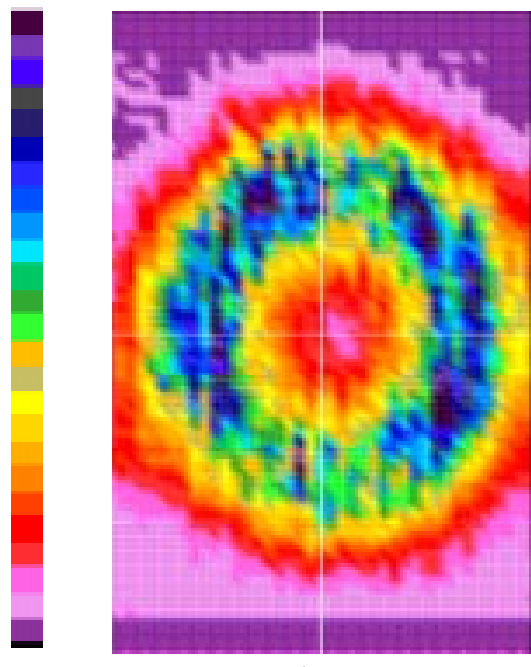

$\mathrm{z}=6 \mathrm{~mm}$

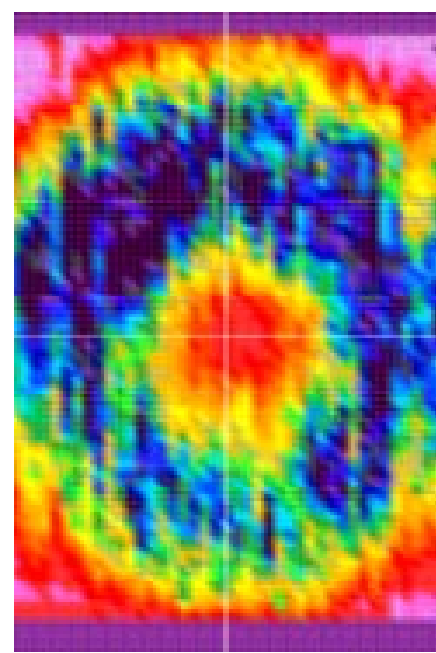

$\mathrm{z}=9 \mathrm{~mm}$

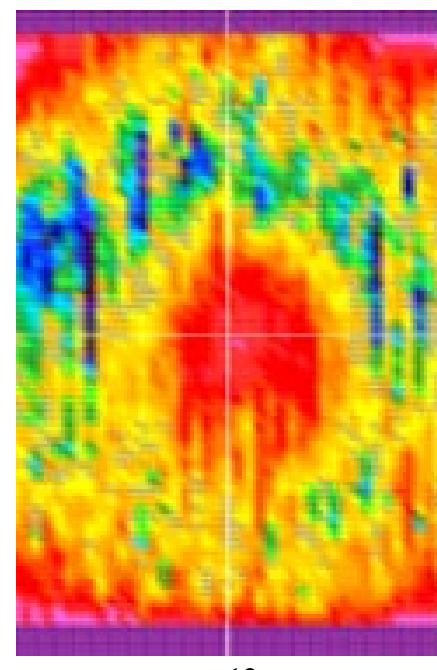

$\mathrm{Z}=12 \mathrm{~mm}$

Figure 12.-End-on views showing fuel distribution (via fluorescence) at different axial distances, $\mathrm{z}$, from the fuel injector. $\mathrm{T}_{\mathrm{in}}=640 \mathrm{~K}, \mathrm{P}_{\mathrm{in}}=5.5 \mathrm{~atm}, \phi=0.45$. 
Public reporting burden for this collection of information is estimated to average 1 hour per response, including the time for reviewing instructions, searching existing data sources, gathering and maintaining the data needed, and completing and reviewing the collection of information. Send comments regarding this burden estimate or any other aspect of this collection of information, including suggestions for reducing this burden, to Washington Headquarters Services, Directorate for Information Operations and Reports, 1215 Jefferson Davis Highway, Suite 1204, Arlington, VA 22202-4302, and to the Office of Management and Budget, Paperwork Reduction Project (0704-0188), Washington, DC 20503.

\begin{tabular}{|l|c|r|}
\hline 1. AGENCY USE ONLY (Leave blank) & $\begin{array}{c}\text { 2. REPORT DATE } \\
\text { June } 1997\end{array}$ & $\begin{array}{r}\text { 3. REPORT TYPE AND DATES COVERED } \\
\text { Technical Memorandum }\end{array}$ \\
\hline
\end{tabular}

4. TITLE AND SUBTITLE

Imaging Fluorescent Combustion Species in Gas Turbine Flame Tubes: On

Complexities in Real Systems

6. $\operatorname{AUTHOR}(\mathrm{S})$

Y.R. Hicks, R.J. Locke, R.C. Anderson, M. Zaller, and H.J. Schock

7. PERFORMING ORGANIZATION NAME(S) AND ADDRESS(ES)

National Aeronautics and Space Administration

Lewis Research Center

Cleveland, Ohio 44135-3191

9. SPONSORING/MONITORING AGENCY NAME(S) AND ADDRESS(ES)

National Aeronautics and Space Administration

Washington, DC 20546-0001
5. FUNDING NUMBERS

WU-537-05-20

8. PERFORMING ORGANIZATION REPORT NUMBER

E-10788

10. SPONSORING/MONITORING AGENCY REPORT NUMBER

NASA TM-107491

AIAA-97-2837

\section{SUPPLEMENTARY NOTES}

Prepared for the 33rd Joint Propulsion Conference and Exhibit cosponsored by AIAA, ASME, SAE, and ASEE, Seattle, Washington, July 6-9, 1997. Y.R. Hicks, R.C. Anderson, and M. Zaller, NASA Lewis Research Center; R.J. Locke, NYMA, Inc., 2001 Aerospace Parkway, Brook Park, Ohio 44142 (work funded by NASA Contract NAS3-27186); H.J. Schock, Michigan State University, East Lansing, Michigan. Responsible person, Y.R. Hicks, organization code 5830, (216) 433-3410.

12a. DISTRIBUTION/AVAILABILITY STATEMENT $\quad$ 12b. DISTRIBUTION CODE

Unclassified - Unlimited

Subject Categories 07, 34 and 35

This publication is available from the NASA Center for AeroSpace Information, (301) 621-0390.

13. ABSTRACT (Maximum 200 words)

Planar laser-induced fluorescence (PLIF) is used to visualize the flame structure via $\mathrm{OH}, \mathrm{NO}$, and fuel imaging in kerosineburning gas turbine combustor flame tubes. When compared to simple gaseous hydrocarbon flames and hydrogen flames, flame tube testing complexities include spectral interferences from large fuel fragments, unknown turbulence interactions, high pressure operation, and the concomitant need for windows and remote operation. Complications of these and other factors as they apply to image analysis are considered. Because both $\mathrm{OH}$ and gas turbine engine fuels (commercial and military) can be excited and detected using $\mathrm{OH}$ transition lines, a narrowband and a broadband detection scheme are compared and the benefits and drawbacks of each method are examined.

14. SUBJECT TERMS

Planar Laser-Induced Fluorescence; Applied Optical Measurements; Aviation Gas Turbine Combustors

15. NUMBER OF PAGES 18

16. PRICE CODE

A03

\begin{tabular}{|c|c|c|}
\hline $\begin{array}{c}\text { 17. SECURITY CLASSIFICATION } \\
\text { OF REPORT } \\
\text { Unclassified }\end{array}$ & $\begin{array}{c}\text { 18. SECURITY CLASSIFICATION } \\
\text { OF THIS PAGE } \\
\text { Unclassified }\end{array}$ & $\begin{array}{c}\text { 19. SECURITY CLASSIFICATION } \\
\text { OF ABSTRACT } \\
\text { Unclassified }\end{array}$
\end{tabular}

NSN 7540-01-280-5500 